This is a peer-reviewed, accepted author manuscript of the following article: Clarke, J. A., McGhee, R., \& Svehla, K. (2020). Opportunity mapping for urban scale renewable energy generation. Renewable Energy.

https://doi.org/10.1016/j.renene.2020.08.060

\title{
Opportunity mapping for urban scale renewable energy generation
}

\section{Abstract}

As part of a project awarded to Glasgow City Council by Innovate UK, a GIS-based Geospatial Opportunity Mapping (GOMap) tool was developed to enable the identification of land throughout the city of Glasgow that is both policy unconstrained and technically feasible in relation to the possible future deployment of Solar Photovoltaic Power Stations (PVPS).

To evaluate the suitability of a specific site, two sets of constraints are considered: one addresses the technical aspects that may constrain the economically achievable power capacity; the other addresses the policy aspects that may affect the likelihood of receiving planning permission for an otherwise technically feasible scheme. Overall technical and policy ratings are determined and the outcome displayed on a $10 \mathrm{~m} \times 10 \mathrm{~m}$ grid across the city. The output maps allow users to determine the overall suitability of any given site and identify the specific technical or policy aspects that might impede a proposed deployment. Application of GOMap to the city of Glasgow indicated that the potential contribution of deploying PVPS on unconstrained Vacant and Derelict Land is equivalent to the annual heating energy requirement of $21.8 \%$ of dwellings in the hard-to-heat category. This finding is significant in relation to the Scottish Government's energy strategy that calls for the electrification of building heating in a manner that alleviates fuel poverty. Alternatively, the 
generated energy is equivalent to $26.6 \%$ of the energy requirement of Glasgow's car fleet if this was converted to electric vehicles.

The paper describes the scoring and weighting methods as applied to the policy and technical aspects and their underlying factors, and presents the outcome of an application of GOMap to quantify the PVPS potential for the city of Glasgow. GOMap is made available under an open source licence and is free to download and apply.

\section{Keywords}

PV power station; urban land identification; technical/policy rating; GIS opportunity mapping.

\section{Symbols and abbreviations}

\section{GW \\ Gigawatt}

$\mathrm{GWh} / \mathrm{y}$

Gigawatt-hours per year

$\mathrm{km}$

Kilometre

\section{$\mathrm{kW}$}

Kilowatt

\section{$\mathrm{kWh} / \mathrm{m}^{2} . \mathrm{y} \quad$ Kilowatt-hours per square metre per year}
$\mathrm{kV}$
Kilovolt

$\mathrm{m}$

Metre

MW Megawatt

MWh/y Megawatt hours per year

$\mathrm{W} / \mathrm{m}^{2} \quad$ Watts per square metre

CAA Civil Aviation Authority

EV Electric Vehicles

7 GCC Glasgow City Council

8 GIS Geographic Information System

9 GOMap Geospatial Opportunity Mapping 
Ground Source Heat Pump

51

53

54

55

56

57

\section{Introduction} energy generation.
PV

PVPS

Photovoltaic

Photovoltaic Power Station

QGIS Quantum Geographic Information System

SPEN Scottish Power Energy Networks

SSSI Sites of Special Scientific Interest

STA Solar Trade Association

VDL Vacant and Derelict Land

As part of the Future City Glasgow Demonstrator Project [1], GCC commissioned the Energy Systems Research Unit at the University of Strathclyde to develop a procedure for the production of geospatial opportunity maps for urban renewable energy schemes. The developed application, GOMap, is made available at no cost under an open source licence [2]. The intention was that these maps be made publicly available to indicate city areas where community-scale renewable energy projects could most readily be developed while, at the same time, highlighting the challenges to be overcome at other locations. Once established, GOMap was utilised to assess the potential for deploying PVPS at sites throughout Glasgow designated VDL. This designation is given to land that at one time had been used for housing or industry but is now a priority for putting to productive use - in this context renewable

Many previous efforts on city site selection for the deployment of renewable energy projects have focused on technical constraints such as the energy resource potential, terrain suitability and access to power grid transmission lines [3] [4] [5] [6]. Other contributions have considered additional constraints related to environmental, social and economic issues [7] [8] [9] [10]. However, at the time of project commencement no prior work could be identified that mapped opportunities for renewable energy systems deployment as a function of the 
various policy issues considered by UK local authority planners and the technical constraints considered by local utility providers. This project addressed both aspects together and required significant collaboration with the local authority (GCC) and utility provider (SPEN), both of whom provided high-quality data that was subsequently embedded in GOMap.

Urban PV systems are typically deployed on roofs and integrated into a building's electricity supply, with the generated power constrained by the available surface area. This approach has advantages in the urban context because it is not unsightly and can be realised with relatively low disruption. The focus of this project was the feasibility of a complementary approach: the deployment of PVPS on VDL as a means to facilitate power generation within clusters located throughout the city, thereby increasing the available surface area and improving energy equity. As the technology does not require deep foundations, panels can be held in place with ground anchors that minimise the environmental impact. Beyond the household level, the Scottish Government had, at the time of project commencement, set a target of 1 GW of locally-owned renewable energy to be deployed by 2020, with an additional $1 \mathrm{GW}$ targeted for 2030 [11].

When evaluating the suitability of a site for PVPS deployment, two issues must be considered. The first is technical - not the soundness of the technology itself but the constraints imposed by the location on the accessible power output. Assuming that these can be managed, the policy factors that might diminish the likelihood of receiving planning permission need to be understood by potential developers.

GOMap considers 5 policy aspects - environmental designation, development zoning designation, glare that might constitute a safety risk, the existence of endangered species, and the visual impact on neighbouring housing; and 4 technical aspects - the connection distance to an electricity substation, the degree of congestion at the substation, the extent of site shading, and terrain access difficulty. With multiple possible factors affecting each of these 
policy and technical aspects, the core aim of GOMap is to score and weight these factors to give a realistic screening of all possible locations throughout a city.

For each location within a city-wide $10 \mathrm{~m}$ x $10 \mathrm{~m}$ grid, the factors underlying the policy aspects are scored on a 3-point scale as being 'possible', 'intermediate' or 'sensitive', while the factors underlying the technical aspects are scored as being 'favourable', 'likely' or 'unlikely'. In the case of the Environmental aspect, a 'showstopper' score is imposed on an underlying factor where it would be impossible to implement a mitigating action. After the individual factor scores are assigned, they are combined as described below to give an overall aspect score and then the aspect scores are combined to give overall policy and technical ratings.

GOMap offers alternative methods to determine the aspect scores corresponding to three use cases - termed 'lenient', 'stringent' and 'prescribed'. The lenient method is intended to encourage development, the stringent method imposes pragmatic constraints, while the prescribed method supports the exploration of future policy changes and possible infrastructure developments by allowing the imposition of user-defined weightings to the policy and technical aspect scores. While the technical aspects and their underlying factors will vary between renewable technologies (e.g. between PVPS and GSHP district heating), they will not vary by location: the method for PVPS deployment assessment can therefore be used directly for another city. Conversely, each local authority has its own policy approach so that the scoring and weighting criteria implemented for Glasgow may need to be modified for another city. GOMap supports this modification. The factor scoring and aspect weighting schemes for this project were developed in collaboration with specialists from the GCC Planning Department and SPEN.

GOMap is built on top of the open source QGIS framework [12], a mapping application which supports the viewing, editing and analysis of geospatial data. These data are stored in shapefiles containing points, lines or polygons for vector representation when loaded into a 
GIS environment. Shapefiles can be combined, filtered, used in calculations and formatted according to need. In GOMap colour is used to highlight any geographical variation in the ratings: darker shades represent increasing barriers to PVPS deployment.

Figure 1 shows a typical GOMap user session in which specific policy and/or technical factors can be weighted or disabled and the corresponding land areas categorised and quantified. Suitable sites can then be assessed for renewable energy generation based on an in-built PVPS model. The central image depicts the Glasgow City boundary with all aspects scored by the lenient method and displayed as a combined policy/technical rating.

Supplementary shapefiles are included in GOMap to provide contextual information such as city buildings, electric power lines and municipality boundary lines and to support factor scoring. The panel to the left in Figure 1 allows individual aspect factors to be disabled while the panel on the right allows aspects to be weighted. For the active factor scope and aspect weightings, the lower left panel reports the available land, colour coded by availability, along with an estimate of the energy production potential of the selected technology (here PVPS although GOMap has access to models for other renewable energy technologies).

The paper is divided into six sections. Section 2 and 3 describes the rules applied to score and weight the factors that underpin the policy aspects (as devised in collaboration with GCC Planners) and the technical aspects (as devised in collaboration with SPEN electricity network personnel). These rules are embodied in the GOMap shapefiles and may be readily modified to accommodate different policy and technical viewpoints on a city-wide scale as described in Section 4. Section 5 presents the results when GOMAP is focused on Glasgow VDL sites. Finally, Section 6 summarises the project findings and provides concluding remarks.

\section{Scoring policy aspects}

Five policy aspects, each comprising several factors, affect whether a site is suitable for development: Environmental; Developmental; Visual intrusion; Biodiversity; and Visual impact. These aspects are now considered in turn. 


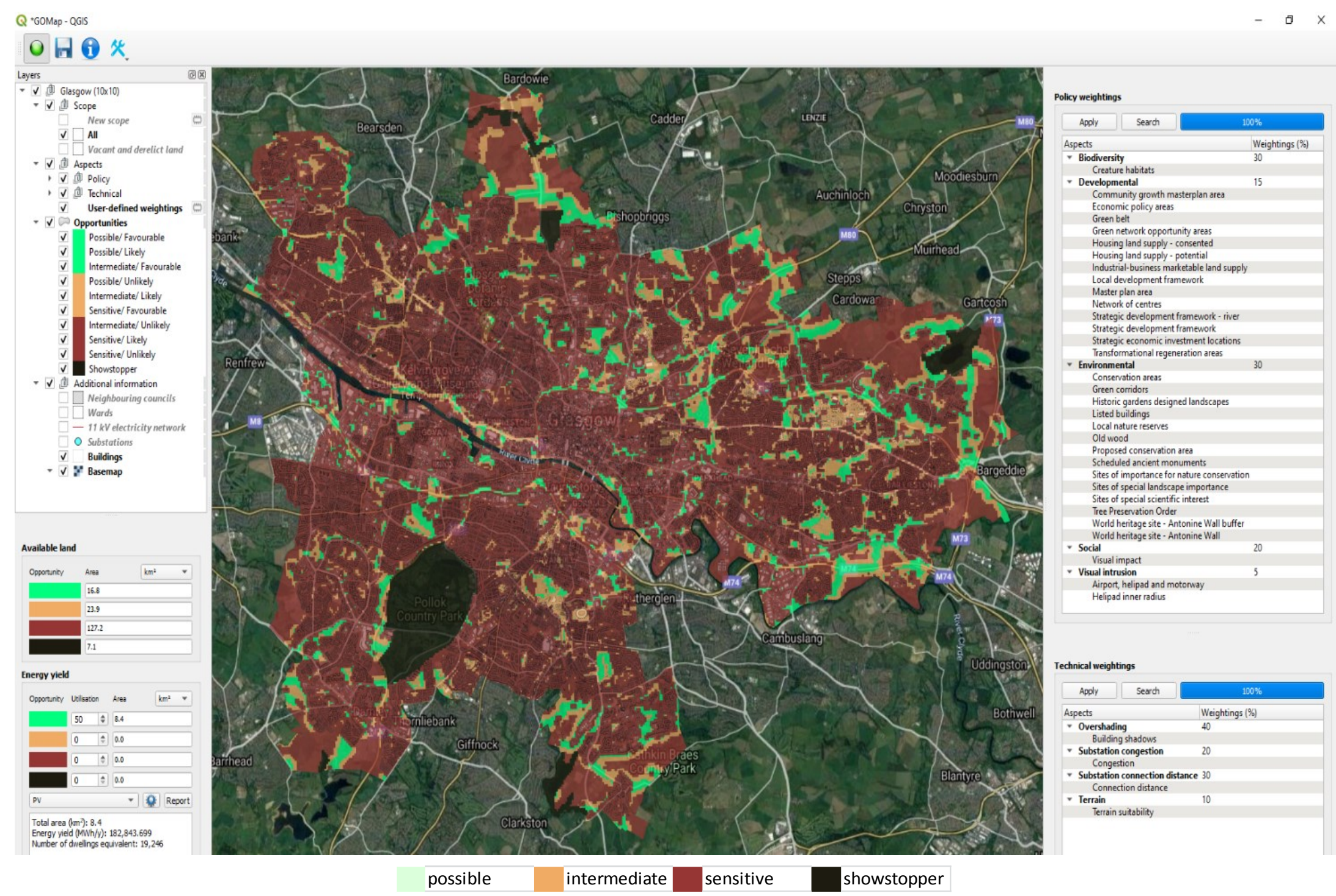

Figure 1: A GOMap session with the focus on Glasgow City. 


\subsection{Environmental aspect}

155

Showstopper
Sensitive

GCC has 13 factors covering this aspect, with each factor represented by a maintained shapefile. These shapefiles are transferred electronically to GOMap and associated with a scoring method based on a consensus view from city planners as to how significant is the hurdle each factor implies. The assigned scores are as follows.

\begin{tabular}{lcl}
\hline Rating & Score & Factor \\
\hline Possible & 1 & Green corridors; Local nature reserves. \\
Intermediate & 2 & Conservation areas; Listed buildings; Ancient woodlands; Tree \\
& & $\begin{array}{l}\text { preservation orders; World Heritage site buffer zone. } \\
\text { Sensitive }\end{array}$ \\
& 3 & $\begin{array}{l}\text { Sites of special landscape importance; Gardens and designed } \\
\text { landscapes; Scheduled ancient monuments; Sites of importance for }\end{array}$ \\
& & nature conservation. \\
& & Sites of Special Scientific Interest; World Heritage site (Antonine \\
& & Wall).
\end{tabular}

For an area where more than one factor applies, the overall aspect score is derived from application of the following rules.

- If three or more scores are intermediate, the overall aspect score is 3. GCC issues a revision.

\subsection{Developmental aspect}

GCC has 14 factors covering this aspect and, as above, the corresponding shapefiles are 
personnel. In general, this aspect is less onerous than the previous one and no factor is rated

171 as a showstopper. The assigned scores are as follows.

\begin{tabular}{lll}
\hline Rating & Score & Factor \\
\hline Possible & 1 & Master plan area; Strategic economic investment locations; \\
& & Transformational regeneration areas. \\
Intermediate & 2 & Community growth masterplan area; Economic policy areas; \\
& & Green belt; Green network opportunity areas; Housing land \\
& & supply; Industrial-business marketable land supply; Local \\
development framework; Network of Centres; Strategic \\
development framework; Strategic development framework - river. \\
Sensitive
\end{tabular}

For areas with multiple factor scores, the same rules as for the Environmental aspect apply.

The 14 shapefiles in GOMap cover the whole city and are automatically updated each time GCC issues a revision.

\subsection{Visual intrusion aspect}

Strong glare from reflections can cause flash blindness and temporary vision loss. The UK

177 Civil Aviation Authority (CAA) in its interim guidance on solar PV systems recognises this but currently offers no quantitative standard as to what may or may not be acceptable. It has been reported that flash blindness for a period of $4-12$ seconds can result from $7-11 \mathrm{~W} / \mathrm{m}^{2}$ reaching the eye [13]. However, the risk of encountering this intensity from solar PV is low only $2 \%$ of the incident energy is reflected, which at the latitude of Glasgow would equate to a maximum of $20 \mathrm{~W} / \mathrm{m}^{2}$ close to the panels. In the US, solar PV farms have been installed at a number of airports without any reported incidents of glare affecting pilots [14]. Analysis of glare from systems with solar concentrators indicates that at ground level people are safe from flash blindness at a distance of $45 \mathrm{~m}$ [15]. However, the existing regulations require CAA to 
be consulted for major solar PV developments within $24 \mathrm{~km}$ of an officially safeguarded aerodrome such as Glasgow Airport, although the aerodrome may choose to reduce this distance to $5 \mathrm{~km}$. Glasgow's Aerodrome Traffic Zone also covers a radius of just less than 5 $\mathrm{km}$. A report from the STA stated that glare from solar panels has not been an issue within airports with local PVPS deployments [16]. As PV panels are designed to absorb light, their reflectivity is considerably lower than that of other objects commonly visible on and around aerodromes such as building facades, metal roofs and bodies of water. Additionally, prior to landing, the nose of a commercial aircraft is tilted slightly upwards making it less likely that reflections from panels would enter the cockpit no matter the orientation of the PV array.

With this in mind, and with the intention of taking a conservative view, the following scores were implemented in GOMap.

\begin{tabular}{lcl}
\hline Rating & Score & Factor \\
\hline Possible & 1 & All other areas.
\end{tabular}

Intermediate 2 Between 1 and $5 \mathrm{~km}$ radius to the south of an airport or heliport or within $100 \mathrm{~m}$ of a motorway.

Sensitive $\quad 3$ Within a $1 \mathrm{~km}$ radius semicircle to the south of an airport or heliport, or $100 \mathrm{~m}$ from a runway.

This shapefile covers the entire city but is specific to PV systems; its applicability would require to be reviewed for other solar technologies such as concentrating mirrors. The CAA intend to update their guidance after the US Federal Aviation Authority completes their own review, which has been under way since October 2013, and this shapefile would need to be revised to reflect any new guidance.

\subsection{Biodiversity aspect}

The habitats of protected or endangered species are not necessarily covered by an environmental designation such as SSSI, and habitats can change over time faster than formal designations. The UK legislation in the Wildlife \& Countryside Act 1981, the Habitats 
Regulations 1994, and Protection of Badgers Act 1992 mandates specific environmental surveys to be carried out if a site is thought to harbour certain species, and a planning application may be turned down if no suitable mitigation measures can be found. This legislation is reflected in guidance from Scottish Natural Heritage [17] and in GCC's Local

Biodiversity Action Plan [18]. The assigned scores for this aspect are as follows.

\begin{tabular}{lcl}
\hline Rating & Score & Factor \\
\hline Possible & 1 & No species on the protected list believed to occur. \\
Intermediate & 2 & UK protected species possibly occur, requires environmental \\
& & survey and mitigation measures. \\
Sensitive & 3 & European protected species possibly occur, requires environmental \\
& & survey and serious mitigation measures.
\end{tabular}

Information about species likely to occur in Glasgow is held by the Land and Environmental Services department at GCC. This information is sensitive so is released on a site-by-site basis. While GOMap includes scores for each location, no details are held on the species in question. Advice from the GCC Land and Environmental Services department is that some general issues with PVPS need to be considered in terms of biodiversity impact:

- the amount of ground disturbance for installation fixings such as poles or platforms;

- the size of the panels, which will cause habitat shading; and

- the density of panels, which will determine the shading extent and impact on access to The following rules are invoked for areas with multiple factor scores.

- Where several species are present, the highest score applies.

- Where three or more species score intermediate, the overall score is 3. plan is issued. 
227 PV arrays can take up a large area, but they are not tall: in an urban environment they are unlikely to significantly impact on the quality of view. A distinction can be made between sites that are not overlooked by residential areas, where the view from residential areas is an existing industrialised landscape or where there is suitable screening; and sites where the introduction of PVPS would significantly change the character of the view from existing dwellings. Establishing which applies at a given site requires subjective judgement, reflected in the simplified scoring criteria implemented in GOMap.

A qualitative judgement is made based on the proximity of residential properties and a rating of the present view, e.g. a large PVPS will be more intrusive against a park background than against a street landscape. Elevation effects are taken into account, with longer visibility from tall buildings or rising ground. To this end, a shapefile comprising all city dwellings is included in GOMap and this is processed against the following factor scores.

\begin{tabular}{lcl}
\hline Rating & Score & Factor \\
\hline Possible & 1 & No residential areas overlook the site. \\
& & \\
Intermediate & 2 & Residential areas overlook the site.
\end{tabular}

This shapefile applies to surveyed sites only and is updated after any nearby development has taken place.

\section{Scoring technical aspects}

There are 4 technical aspects considered by GOMap: Substation distance; Grid congestion; Site shading; and Terrain suitability.

\subsection{Substation distance aspect}

The local distribution network operator, SPEN, publishes guidelines on connection opportunities for renewable energy generation [19]. An urban PVPS could be connected to the grid at a primary or secondary substation, or at some point on an $11 \mathrm{kV}$ circuit. Only 
installations of less than $12 \mathrm{kV}$ can be connected to the low voltage network and this is too small a scale for PVPS. In general, the location and cost of a possible grid connection must be determined for each project as it depends on multiple considerations around the capacity and type of equipment proposed for the installation as well as on the layout of nearby $11 \mathrm{kV}$ circuits and secondary substations.

SPEN operates 74 primary substations in the city or immediately adjacent to its boundary, and each of these is at the centre of around a dozen $11 \mathrm{kV}$ circuits feeding many secondary substations. The density of the circuits is higher close to the substation so that the probability of there being a suitable secondary substation or an accessible section of circuit will be higher the closer a site is to a primary substation, and a criterion based on the straight-line distance to the nearest $11 \mathrm{kV}$ circuit will give a sufficient indication of the relative suitability of different sites. It should be noted that this is not the actual distance covered by a connection cable, which must be routed along roadsides. Although calculating the real grid distance through the streets to the nearest accessible circuit is a viable analysis in GOMap, this was not implemented for this project as a feasibility study would be required to determine the ideal route for installing connection cables in light of the logistics involved (i.e. traffic redirection, pedestrian access, commercial business impact etc.). Therefore, a criterion based on the straight-line distance to the nearest $11 \mathrm{KV}$ circuit was deemed to provide a sufficient indication of the relative suitability of different sites. Glasgow has a surface area of around $750 \mathrm{~km}^{2}$, giving an average density of one primary substation per $12.5 \mathrm{~km}^{2}$, roughly the area of a circle with a $2 \mathrm{~km}$ radius. This statistic led to the following factor scores.

\begin{tabular}{lcl}
\hline Rating & Score & Factor \\
\hline Favourable & 1 & Within $100 \mathrm{~m}$ of a substation connection line. \\
Likely & 2 & Between $100 \mathrm{~m}$ and $200 \mathrm{~m}$ of a substation connection line. \\
Unlikely & 3 & Further than $200 \mathrm{~m}$ from a substation connection line. \\
\hline
\end{tabular}


This shapefile covers the whole city, and is applicable to any renewable generation technology. It is updated each time SPEN revise their list of substations for Glasgow.

\subsection{Grid congestion aspect}

Even if there is a substation close by, it still may not be possible to connect if the existing circuits are overloaded or if there are already significant connections with the possibility of reverse current flow. This factor is distinct from the grid connection distance because the situation may change over time as loads change and substations are upgraded.

SPEN assesses congestion around primary substations from two perspectives: the ability of each $11 \mathrm{kV}$ circuit to take distributed generation (Circuit level), and the impact of distributed generation on other circuits (Primary Area level) [20]. The company publishes GIS-based

Network Heat Maps, which score each circuit at each substation on a 3-point scale for each of 7 issues. On examination, however, the heat maps show no variation between the different circuits at any substation in the Glasgow area.

The total score for any substation could therefore theoretically range from 7 (best) to 21 (worst) but in practice all the scores for the 74 primary substations in or immediately adjacent to Glasgow fall between 8 and 12, with 10 being the most frequent score. Hence, the factor scoring applied in GOMap for Glasgow is as follows.

\begin{tabular}{lcl}
\hline Rating & Score & Factor \\
\hline Favourable & 1 & Combined heat map score under 10. \\
Likely & 2 & Combined heat map score equal to 10. \\
Unlikely & 3 & Combined heat map score greater than 10. \\
\hline
\end{tabular}

This shapefile covers the entire city and is applicable to any renewable generation technology.

It is updated each time SPEN issue revised Network Heat Maps for Central and Southern Scotland (www.spenergynetworks.co.uk/pages/dg_spd_heat_maps_terms.aspx). 


\subsection{Site shading aspect}

290

291

292

293

294

295

296

297

298

299

300

301

302

303

304

305

Solar PV generation depends on panel solar irradiation and if a part of an array connected to an inverter is shaded then the whole array output can fall significantly.

The shading caused by an adjacent building varies throughout the day and year, and a detailed assessment of the shadow footprint needs to be made during the design stage using high resolution modelling software. In GOMap, a daily footprint is determined from a shapefile containing all city buildings coupled with an Ordnance Survey Digital Surface Model [21] for the Summer and Winter solstices and the Spring and Autumn equinoxes: a composite annual footprint is then estimated by superimposing the outcomes. On examination, the difference between the annual footprint and that for Spring, Summer and Autumn only was generally less than $10 \mathrm{~m}$ in width. For this reason, it was decided not to attempt to include an intermediate score. The annual footprint shows the areas that will be shaded by surrounding buildings at some point over the year but does not imply that all of the area will be shaded all of the time. It also does not give a definitive answer on where there will be problems with shading caused by trees, large signs or hoardings, which are included in the Digital Surface

Model. So it is not a substitute for a rigorous calculation of annual energy availability; however, the footprint does give an indicator of where it is most useful to look more closely.

\begin{tabular}{lcl}
\hline Rating & Score & Factor \\
\hline Favourable & 1 & Falls outside the estimated annual shaded footprint. \\
Unlikely & 3 & Falls within the estimated annual shaded footprint.
\end{tabular}

This shapefile covers the entire city and is applicable to all solar technologies. It is updated when a new Ordnance Survey Digital Surface Model is issued.

\section{$3.4 \underline{\text { Terrain suitability aspect }}$}

Most urban land will not present problems for PVPS deployment. There may be sites that have been built around so that there is no road access but this will be rare. A PVPS does not 
require deep foundations and panels can be held in place with gravity anchors if necessary, thus minimising any environmental impact. However, steep slopes or broken ground with limited access, such as a railway cutting or a site liable to flooding [22], will clearly be more difficult to develop.

The information required to score this aspect is generated via a qualitative judgement based on site information using Google Earth, the Digital Terrain Model, and SEPA's interactive flood map [23].

\begin{tabular}{lcl}
\hline Rating & Score & Factor \\
\hline Favourable & 1 & Flat ground, no access issues or risk of flooding. \\
Likely & 2 & Heavily sloping or broken ground; restricted access; unsafe \\
& & buildings; medium risk of river or coastal flooding; high risk of \\
& & surface water over large area. \\
Unlikely & 3 & No direct access; site under water or with high risk of river or \\
& & coastal flooding.
\end{tabular}

These shapefiles cover VDL sites only and are applicable to PVPS. They are updated when, for example, new flood risk assessments are issued.

\section{Glasgow City opportunity mapping}

Policy and technical ratings are established as the median value for the comprising aspect scores, while setting the policy rating to 4 if the related Environmental aspect rating is 4 (showstopper). Where the aspect scoring method is 'lenient', this gives the most optimistic view of the opportunity from a policy perspective and is appropriate where the intention is to encourage sustainable developments. On the other hand, it has the disadvantage of hiding individual aspects with high factor scores as would be exposed by the 'stringent' method. Both these scoring methods and the difference they make to the generated opportunity map is as shown in Figure 2. 


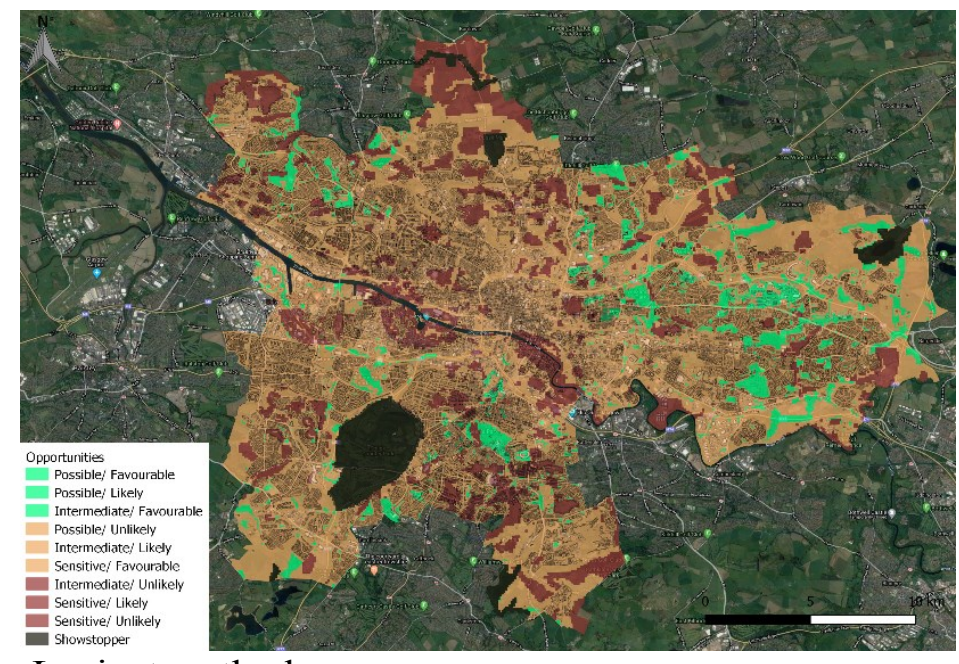

Lenient method
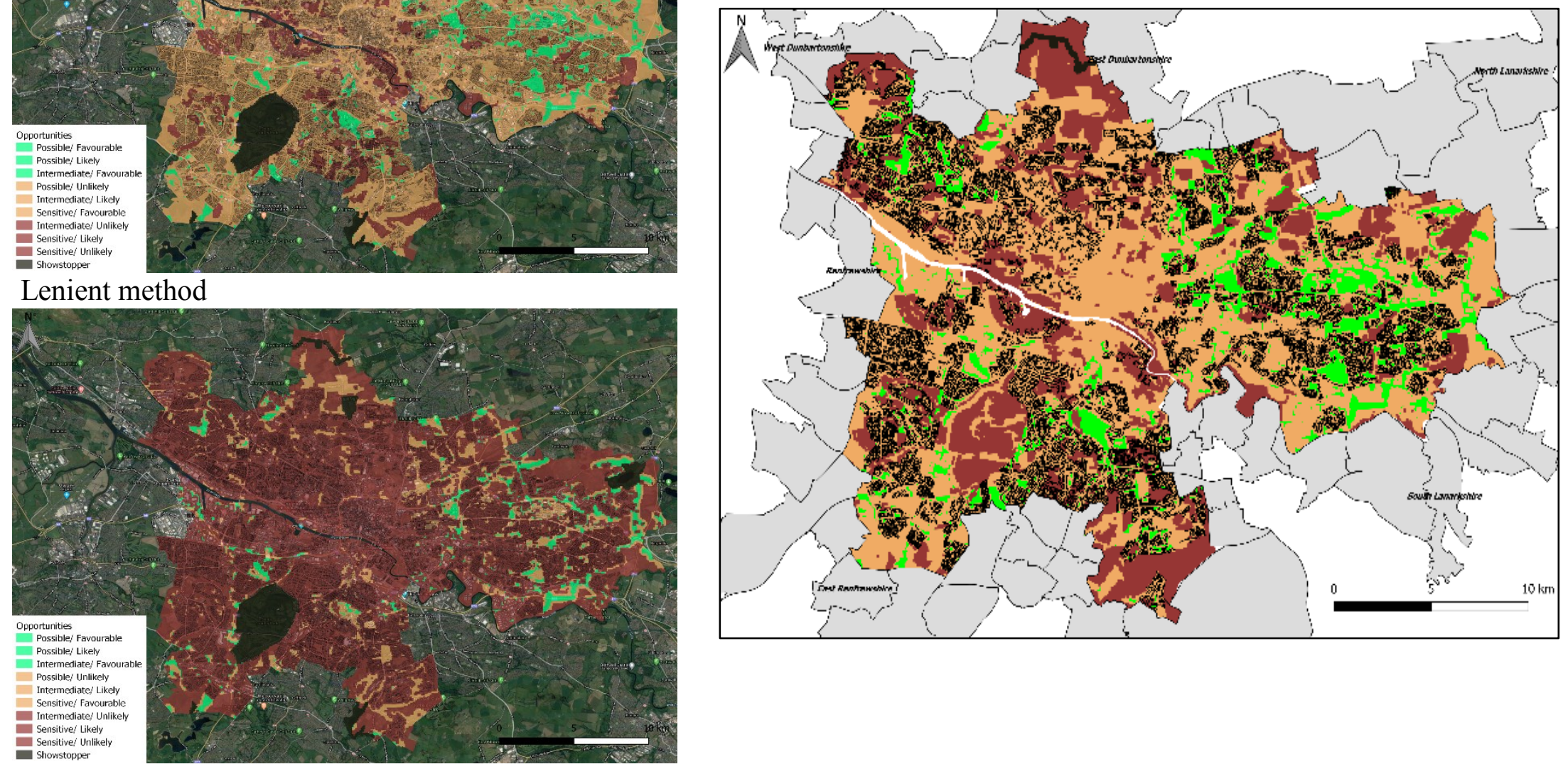

Stringent method

Figure 2: Policy/ Technical ratings citywide by the two scoring methods: lenient (upper left) and stringent (lower left). The right image shows the proximity of housing to the areas with the best rating. 
The land area evaluated in the acceptable (green) category is significantly greater with the lenient method - $16.6 \mathrm{~km}^{2}$ as opposed to $8.2 \mathrm{~km}^{2}$ for the stringent method - a difference of almost 50\%. Within GOMap, it is possible to weight aspect scores as a means to explore the impact on land availability of policy or technical aspect relaxation. The weighting system used in GOMap shares the intent of researchers who utilise GIS software to solve a multicriteria problem. In the approach of overlay analysis, a raster file (an image comprised of pixels) is reclassified by assigning each pixel a value from a suitability scale. Several raster files are then overlaid, the values of each pixel calculated and the results shown in a new raster map. GOMap, conversely, uses shapefiles to achieve the same result. The advantage of this approach is that it allows for a single opportunity map to be shown and updated 'on-thefly' as any policy and technical shapefile can be independently switched on/off and the scores recalculated automatically.

The view of GCC planners is that developers often perceive policy-related aspects as greater barriers than they themselves do and for this reason the lenient scoring method is preferred. However, some of the factors underpinning the Environmental aspect are genuine blockers: for example, the course of the Antonine Wall, which is a World Heritage site.

Because it is not possible to obtain data from different tools when applied to the same urban estate, an inter-model comparison between GOMap and other applications could not be performed. That said, GOMap has been shown to be equivalent to GCC's planning application assessment procedure but with the added advantage of conflation with technical aspects and the flexibility/speed derived from procedure automation. Through the publishing of opportunity maps, the intention is to encourage development proposals that are likely to prove acceptable.

The influence of individual policy aspects can be determined by applying weighting factors, including turning aspects off in various combinations. Table 1, for example, lists the result when the policy aspects are disabled in turn (all other policy and technical aspects remaining 
enabled) and when non-equal weightings are applied to the policy aspects (again with the technical aspects remaining active). These data indicate that the Visual impact aspect is the dominant constraint as this frees up the most land when disabled. By overlaying the City's 'housing' shapefile on the upper left map in Figure 2, it can be seen in the resulting map shown upper right that the reason for this result is that VDL sites, which comprise the majority of otherwise unconstrained sites, are overlooked by housing.

From the result for the policy aspect weighting case, it can be seen that policy weightings that give emphasis to environmental and biodiversity issues at the expense of the other policy aspects considerably increases the available land (in Glasgow at least): for the example given in Table 1, from $16.6 \mathrm{~km}^{2}$ when not weighted to $112.9 \mathrm{~km}^{2}$ when weighted. In practice, $\mathrm{f}$ course, the applied weightings would be the outcome of a consultation process.

Table 1: Impact of disabling and weighting the Policy aspects.

\begin{tabular}{ll}
\hline Aspect disabled & Land rated possible $\left(\mathrm{km}^{2}\right)$ \\
\hline None & 16.6 \\
Visual impact & 32.8 \\
Environmental & 23.0 \\
Developmental & 21.6 \\
Visual intrusion & 21.0 \\
Biodiversity & 16.9 \\
With aspect weighting ${ }^{\#}$ & 112.9 \\
\hline \# 0.3 Environmental +0.3 Biodiversity +0.2 Visual impact \\
+0.15 Developmental + 0.05 Visual intrusion
\end{tabular}

367 In a similar manner, the influence of the individual technical aspects can be quantified as 368 shown in Table 2 (again with all other policy and technical aspects fully enabled in each case). These data indicate that the Site shading aspect is the dominant constraint as its 
removal frees up the most land. That said, for the case of PVPS at least, removing this constrain would not be possible.

Table 2: Impact of disabling and weighting the Technical aspects.

\begin{tabular}{lc}
\hline \multicolumn{1}{c}{ Aspect disabled } & Land rated possible $\left(\mathrm{km}^{2}\right)$ \\
\hline None & 16.6 \\
Site shading & 59.3 \\
Substation distance & 26.9 \\
Grid congestion & 19.9 \\
Terrain suitability & 17.2 \\
With aspect weighting & 33.5 \\
\hline \# 0.4 Site shading +0.3 Substation distance +0.2 Grid congestion \\
+0.1 Terrain suitability
\end{tabular}

372 The application of technical aspect weightings that give a realistic emphasis as shown in

373 Table 2 (with the policy aspects remaining unweighted) increases the available land area to

$374 \quad 33.5 \mathrm{~km}^{2}$ from $16.6 \mathrm{~km}^{2}$ when no weightings are applied. Such a weighting implies that the

375 significance of the last two aspects should be most improved by appropriate infrastructure 376 intervention.

\section{5. Glasgow VDL exploitation opportunity}

378 GOMap was applied to evaluate the suitability of VDL sites for PVPS deployment. Figure 3

379 shows the combined policy and technical ratings for Glasgow in all rated categories and for

380 sites in the most favourable (green) category. In the latter case, this corresponds to a total land area of $1.95 \mathrm{~km}^{2}$ out of a total of $11.3 \mathrm{~km}^{2}$. 


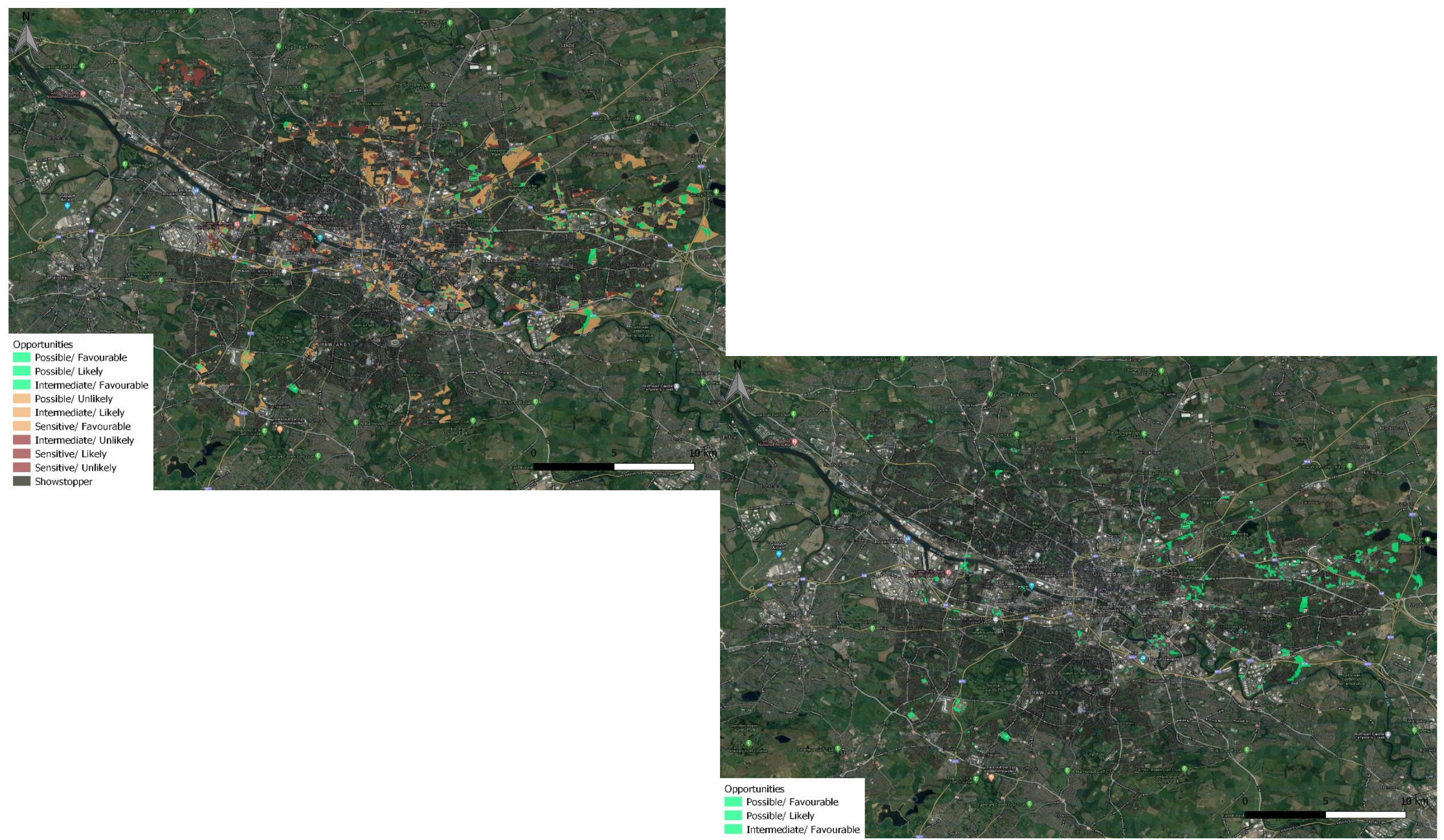

Figure 3: Combined policy and technical scores for VDL sites in Glasgow. The left image shows the distribution of sites in all rated categories; the right the clustering of those in the green category. 
Table 3 indicates how the total VDL area divides by policy and technical ratings in relation to PVPS deployment. Of the total available VDL area in the city, $17.3 \%$ lies in the green category, $66.8 \%$ in the orange category, $15.7 \%$ in the red category, and $0.3 \%$ in the showstopper category.

Table 3: VDL exploitation opportunity $\left(\mathrm{km}^{2}\right)$.

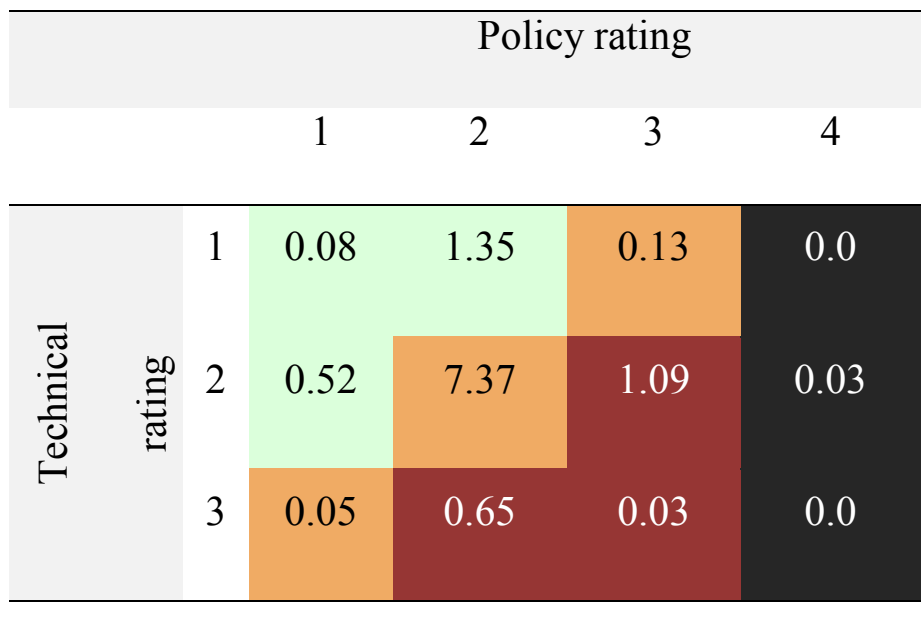

The land areas indicated green in Table 3 were processed by GOMap's in-built PVPS hourly output estimator: Table 4 shows the annual PVPS energy yield for each of the 3 rating categories (expressed in energy and dwelling/EV equivalent terms) and under the following PVPS deployment assumptions:

- $50 \%$ of the available land at a given site can be utilised;

- the total number of PV panels is determined by searching for the optimum panel inclination angle and inter-array spacing to avoid panel shading $\left(40^{\circ}\right.$ and $7.7 \mathrm{~m}$ respectively for Glasgow).

With these assumptions, a new shapefile is generated containing PV panels within the boundary of all suitable land for each of the 3 rating categories. The embedded PVPS model calculates the annual energy yield at $165 \mathrm{kWh} / \mathrm{m}^{2} . \mathrm{y}$. Using a standard dimension PV panel of $2 \times 1 \mathrm{~m}$, the combined energy produced from the total number of panels is determined. 
The average heating energy demand of a dwelling in Glasgow is estimated from the Scottish Energy Statistics database [24], which gives the domestic energy consumption for Glasgow City as 3,895 GWh/y of which the space heating component of an average household's energy consumption is $74.1 \%$ or $2,886 \mathrm{GWh} / \mathrm{y}$. Given that the number of occupied dwellings is around 300,000, this gives the average heating demand for a Glasgow dwelling of 9.5 $\mathrm{MWh} / \mathrm{y}$. It is further assumed that heating will be increasingly electrified in future (e.g. via heat pumps) in line with the Scottish Government's energy strategy [25].

The average energy demand of an electric vehicle in the UK is $1.5 \mathrm{MWh} / \mathrm{y}$ [26].

Table 4: Estimated annual energy yield for VDL PVPS deployment.

\begin{tabular}{lcccc}
\hline Policy/ Technical rating & VDL & Energy & No. dwellings & No. EVs \\
& area & yield & equivalent & equivalent \\
& $\left(\mathrm{km}^{2}\right)$ & $(\mathrm{GWh} / \mathrm{y})$ & & \\
\hline possible/ favourable & 0.08 & 3.0 & 312 & 1,979 \\
possible/ likely & 0.52 & 20.4 & 2,144 & 13,576 \\
intermediate/ favourable & 1.35 & 53.1 & 5,594 & 35,427 \\
Total & 1.95 & 76.5 & 8,050 & 50,982
\end{tabular}

To place these results in context, Glasgow has around 300,000 dwellings of which around $123,000(41 \%)$ are socially owned and, of these, 37,000 (30\%) have no wall insulation and are in the hard-to-heat category [27]. The potential contribution of VDL-deployed PVPS is therefore estimated at $2.7 \%, 6.5 \%$ and $21.8 \%$ of the city's total, social and hard-to-heat housing stock respectively. This last figure is most significant in light of the Scottish Government's energy strategy, which calls for the electrification of building heating in a manner that alleviates fuel poverty. Any final decision on PVPS deployment would, of course, depend on the cost-effectiveness of specific deployments and issues associated with the lost opportunities for other VDL site utilisation. Alternatively, and given that Glasgow households have access to 0.64 cars on average [19], the energy yield of Table 4 would cover 
$26.6 \%$ of Glasgow's car fleet if this was converted to EVs. It was also observed from the

425 GOMap outputs that acceptable VDL sites are highly correlated with areas where public EV charge points will be required in future.

427

428

430

431

432

433

\section{Conclusions}

An urban-scale renewable energy opportunity map generator has been developed based on GIS technology loaded with shapefiles corresponding to policy and technical factors that are scored at $10 \mathrm{~m} \times 10 \mathrm{~m}$ resolution across the city of Glasgow. The method of scoring was established in collaboration with specialists from GCC's Planning Department and SPEN electricity grid specialists. The opportunity map generator, which is available at no cost under an open source licence, was applied to the city of Glasgow to determine the opportunity for the deployment of PVPS at sites assigned the VDL designation. The outcome indicated a possible space heating energy contribution equivalent to $2.7 \%$ of Glasgow's total housing stock, $6.5 \%$ of social housing and $21.8 \%$ of dwellings in the hard-to-heat category. Alternatively, the generated energy could power $26.6 \%$ of Glasgow's car fleet if this was converted to EVs.

Although the GOMap application has here been reported for PVPS deployments at sites designated VDL, it has also been used to assess PV canopies applied to city multi-storey car parks. By varying the policy and technical scoring and weighting criteria, other technologies can be assessed, such as district heating schemes [28] [29] or city geothermal energy [30] [31], and alternative policy considerations imposed to reflect the planning requirements of other cities. It is anticipated that the Open Source nature of GOMap will facilitate collaborative development in future.

\section{Acknowledgments}

The authors would like to thank those individuals at GCC and SPEN who advised on the GOMap procedures and its application to the city of Glasgow. Thanks are also extended to Innovate UK, who provided funding for the project. 


\section{References}

451 1. Future City Glasgow Demonstrator project: https://futurecity.glasgow.gov.uk/ (last 452 accessed 21/07/20).

453 2. GOMap download site:

454

455

456

457

458

459

460

461

462

463

464

465

466

467

468

469

470

471

472 for solar hydrogen production sites selection in Algeria', Hydrogen Energy, V44, pp. 31808-

$473 \quad 31831,2019$

\section{https://www.strath.ac.uk/research/energysystemsresearchunit/applications/gomap/ (last} accessed 21/07/20).

3. de Santoli L, Mancini F and Garcia D A, 'A GIS-based model to assess electric energy consumptions and usable renewable energy potential in Lazio region at municipality scale', Sustainable Cities and Society, V46, 2019.

4. Amjad F and Shah L A, 'Identification and assessment of sites for solar farms development using GIS and density based clustering technique - a case study in Pakistan', Renewable Energy, V155, pp. 761-769, 2020.

5. Colak H E, Memisoglu T and Gercek Y, 'Optimal site selection for solar photovoltaic power plants using GIS and AHP: A case study of Malatya Province, Turkey', Renewable Energy, V149, pp. 565-576, 2020.

6. Pillot B, Al-Kurdi N, Gervet C and Linguet L, 'An integrated GIS and robust optimization framework for solar PV plant planning scenarios at utility scale', Applied Energy, V260, 2020.

7. Swofford J and Slattery M, 'Public attitudes of wind energy in Texas: Local communities in close proximity to wind farms and their effect on decision-making', Energy Policy, V38, pp. 2508-2519, 2010.

8. Messaoudi D, Settou N, Negrou B and Settou B, 'GIS based multi-criteria decision making 2019 
9. Marques-Perez I, Guaita-Pradas I, Gallego A and Segura B, 'Territorial planning for photovoltaic power plants using an outranking approach and GIS', Cleaner Production, V257, 2020.

10. Shao M, Han Z, Sun J, Xiao C, Zhang S and Zhao Y, 'A review of multi-criteria decision making applications for renewable energy site selection', Renewable Energy, V157, pp. 377403, 2020.

11. Scottish Government: Renewable Energy for Communities, https://www.gov.scot/policies/renewable-and-low-carbon-energy/local-and-small-scalerenewables/ (last accessed 21/07/20).

12. QGIS download site: https://www.qgis.org/en/site/ (last accessed 21/07/20).

13. Technical Guidance for Evaluating Selected Solar Technologies on Airports, US Federal Aviation Authority, November 2010.

14. Solar photovoltaic energy facilities: Assessment of potential for impact on aviation, Report No 10/344/RPS/1, Spaven Consulting, January 2011.

15. Ho C, Ghanbari, C and Diver R, 'Hazard Analysis of Glint and Glare from Concentrating Solar Power Plants', Proc. SolarSPACES 2009, Berlin, Germany, 2009.

16. Solar Trade Association, Impact of solar PV on aviation and airports: $\underline{\text { http://www.solar- }}$ $\underline{\text { trade.org.uk/wp-content/uploads/2016/04/STA-glint-and-glare-briefing-April-2016-v3.pdf }}$ (last accessed 21/07/20).

17. Scottish Natural Heritage, Protected species A-Z guide:

https://www.nature.scot/professional-advice/safeguarding-protected-areas-andspecies/protected-species/protected-species-Z-guide (last accessed 21/07/20).

18. Glasgow City Council, Local Biodiversity Action Plan:

https://www.glasgow.gov.uk/biodiversity (last accessed 21/07/20). 
19. Scottish Power Energy Networks, New connections,

https://www.spenergynetworks.co.uk/pages/new_connections.aspx (last accessed 21/07/20)

20. Scottish Power Energy Networks, Distributed Generation Heat Maps,

http://www.spenergynetworks.co.uk/pages/connection_opportunities.asp (last accessed 21/07/20).

21. Ordinance Survey, OS Terrain 5: http://www.ordnancesurvey.co.uk/businessgovernment/products/terrain-5 (last accessed 21/07/20).

22. Department for Communities and Local Government, 'Technical Guidance to the National Planning Policy Framework', March 2012.

23. Scottish Environment Protection Agency, Flood Maps:

http://map.sepa.org.uk/floodmap/map.htm (last accessed 21/07/20).

24. Scottish Government, Energy Statistics Database:

https://www2.gov.scot/Resource/0054/00549199.xlsx (last accessed 21/07/20).

25. Scottish Government, Low Carbon Infrastructure Transition Programme:

https://www.gov.scot/policies/renewable-and-low-carbon-energy/low-carbon-infrastructuretransition-programme/ (last accessed 21/07/20).

26. Citizens Advice UK, An analysis of the domestic electric vehicle tariff market:

https://www.citizensadvice.org.uk/Global/CitizensAdvice/Energy/Take\%20Charge\%20\%20EV\%20tariff\%20report.pdf (last accessed 21/07/20).

27. Scottish Government, Scottish house condition survey: 2018 key findings:

https://www.gov.scot/publications/scottish-house-condition-survey-2018-key-findings/ (last accessed 21/07/20).

28. Alexandrov G G and Ginzburg A S, 'Anthropogenic impact of Moscow district heating system on urban environment', Energy Procedia, V149, pp. 161-169, 2018. 
522 29. Leurent M, 'Analysis of the district heating potential in French regions using a geographic 523 information system', Applied Energy, V252, 2019.

524 30. Schiel K, Baume O, Caruso G and Leopold U, 'GIS-based modelling of shallow

525 geothermal energy potential for $\mathrm{CO}_{2}$ emission mitigation in urban areas', Renewable Energy, 526 V86, pp. 1023-1036, 2016.

527 31. Miglani S, Orehounig K and Carmeliet J, 'A methodology to calculate long-term shallow 528 geothermal energy potential for an urban neighbourhood', Energy and Buildings, V159, pp. $529 \quad 462-473,2018$. 